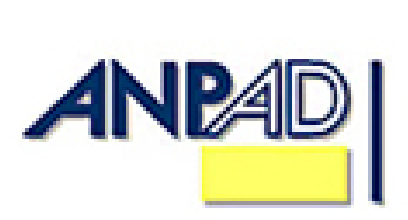

A vailable online at

http://www.anpad.org.br/bar

BAR, Curitiba, v. 7, n. 4, art. 4,

pp. 379-396, Oct./Dec. 2010

\title{
A New Contingency View of the Organization: Mananging Complexity and Uncertainty Through Cognition
}

\author{
Farley Simon Nobre* \\ E-mail address: f.nobre@yahoo.com \\ Universidade Federal do Paraná - DAGA/PPGADM/UFPR \\ Curitiba, PR, B razil.
}

\section{Andrew M. Tobias}

E-mail address: a.m.tobias@bham.ac.uk

The $U$ niversity of Birmingham

Birmingham, UK.

\section{David S. W alker}

E-mail address: d.s.walker@bham.ac.uk

The U niversity of Birmingham

Birmingham, UK.

\begin{abstract}
This paper proposes a new contingency view of the organization and it contributes to the theme through two complementary perspectives. First, it proposes cognition as a function which acts as the main mediator between the organization and the environment. Second, it introduces cognition as the core organizational ability which supports individuals, groups and organizations with intelligence, autonomy, learning and knowledge management, whereas, in such a perspective, cognition is viewed as the core resource in the service of the organization. B oth perspectives, the mediation and the core organizational resource views, imply that cognition contributes toward managing environmental complexity and uncertainty. From this picture, this work analyzes the organization in the pursuit of high degrees of organizational cognition in order to manage high levels of environmental complexity and uncertainty. Grounded in these views, this paper presents a model of the organization as a set of fuzzy abilities. From all these backgrounds, this research opens new directions for future research on organizational abilities which subsume cognition, intelligence, autonomy, learning and knowledge management as important elements of organizational analysis.
\end{abstract}

Key words: organizational ability; cognition; environmental uncertainty; complex systems.

Received 09 February 2009; received in revised 15 A pril 2010.

Copyright (c) 2010 Brazilian A dministration R eview. All rights reserved, including rights for translation. Parts of this work may be quoted without prior knowledge on the condition that the source is identified.

\footnotetext{
* Corresponding author: Farley Simon Nobre

A v. Pref. Lothário M eissner, 632, 2 ${ }^{\text {nd }}$ floor, J ardim B otanico, Curitiba, PR, 80210-170, B razil.
} 


\section{INTRODUCTION}

Studies of complex systems and their classification through hierarchical levels of complexity were proposed by Boulding (1956) and Simon (1996). In these studies, a system is defined as a large number of objects together with relationships between them and between their attributes or properties. The parts, elements or objects that form the systems vary from being very simple to very complex in structure, and from being highly stable to highly dynamic and variable in their interactions. M oreover, each system of higher level of complexity incorporates the features of those systems below it. In such a context, this paper proposes that differences in the levels of complexity of systems reside not only in the properties and structure of their elements, but most importantly, in the abilities of these elements. The former, i.e., properties and structure, refers to physical, biological and chemical attributes of the system, and the latter, i.e., abilities, means cognition, intelligence, autonomy, learning and knowledge management capabilities of the system.

Therefore, analyzing Boulding's (1956) typology, which classifies systems according to their levels of complexity, this research proposes that the higher the complexity of a system on Boulding's classification scale, the higher its degree of cognition (Nobre, Tobias, \& Walker, 2009a, 2009b, 2009c). This classification of Boulding's systems, which is enumerated from 1 to 9 in the order of growth of their levels of complexity, is given as (1) frameworks, (2) clockworks, (3) cybernetic systems, (4) open systems, (5) blueprinted-growth systems, (6) internal-image systems, (7) symbolprocessing systems, (8) social systems and (9) transcendental systems, respectively. A ccording to this typology, levels 1 to 3 include the technical and physical systems. Levels 4 to 6 subsume the biological systems. Levels 7 to 8 involve the human and social systems. Level 9 is any imaginary level. M oving from level 1 to 8 , the systems become progressively more complex and their structures become somewhat less rigid and constrained, and the connections between the interacting parts become relatively loose, where less constraint is placed on the behavior of one element by the condition of the others (Scott, 1998). A dditionally, and most importantly, moving from level 1 to 8 , the systems grow towards higher degrees of cognition.

From these analyses, it can be asserted that differences between theories of natural and social sciences reside not only in the properties and structure of their elements of study, but most importantly, in the abilities of these elements. On the one hand, the main elements of social systems are humans and networks of people, and also organizations and networks of organizations. Social systems possess high degrees of cognition and, consequently, high levels of intelligence, autonomy, learning and knowledge management capabilities, and whereas these abilities are distributed among their individuals and among their relationships. On the other hand, the elements of, and the relationships with, physical, biological and chemical systems, including all the objects and organisms of the ecological system, but excluding man, are less complex than those found in social systems if we consider that they have low degrees of cognition if any in most cases. Therefore, the nature of a theory of organizations resides in principles of human behavior and cognition ${ }^{(1)}$.

Proceeding further, what makes this paper distinct and unique is that it puts forward a new analysis perspective of the organization and the environment, and also of the relations between them through the concepts of cognition and complexity. From this perspective, the paper proposes that cognition is the core asset of the organization since it contributes to control and to reduce the level of environmental complexity and uncertainty. It also contributes by explaining what distinguishes organizational cognition from the concepts of organizational intelligence, autonomy, learning and knowledge management. It most outlines the relations and frontiers between these concepts, and it explains that, despite being distinct, they form complementary abilities. These concepts, all together, form the set of abilities in the organization. Grounded in such a background, this paper presents a model of the organization as a set of fuzzy abilities; however, it also extends this model to the concept of the environment, relations between the organization and the environment, and networks of organizations. 


\section{ORGANIZATION, UNCERTAINTY AND COMPLEXITY}

Environmental uncertainty can be associated with the level of uncertainty that the organization and its participants perceive or sense from the environment (Ducan, 1972). Moreover, the contingency theory (Galbraith, 1973, 1974, 1977, 2002) defines uncertainty as the variable which makes the organization ${ }^{(2)}$ contingent upon the environment ${ }^{(3)}$. Hence, organizational design, and thus organizational choice, depends on the concept of uncertainty. B riefly, uncertainty can be associated with the mathematical concepts of probability and fuzziness (Klir \& Folger, 1988). However, uncertainty can also be associated with propositions of bounded rationality (Simon, 1982a, 1982b, 1997a, 1997b). In this latter perspective, uncertainty carries the meaning of lack of information ${ }^{(4)}$, which leads the organization to unpredictability of outcomes, in addition to insufficiency of cognitive abilities for general information-processing and interpretation (N obre et al., 2009a). The former, lack of information, means that uncertainty is the difference between the total amount of information that the organization needs to have in order to complete a task and the amount of information the organization actually possesses. The latter, insufficiency of cognition, means that uncertainty is the difference between the degree of cognition that the organization needs to have in order to complete a task and the degree of cognition in possession of the organization. These approaches to uncertainty are complementary to each other since the greater the amount of information that the organization needs to have in order to perform and complete a task, the greater is the degree of cognition that the organization needs to have in order to process and manage this information for task execution and completion. Therefore, the question which arises in our quest is: what can we do to control the level of uncertainty that the organization is faced with and needs to manage? This paper implies that organizational cognition plays an important role in such a task (N obre et al., 2009a, 2009b, 2009c).

Complementarily to this view, this paper defines the complexity of the environment and being contingent upon the level of uncertainty that it represents to the organization. Similarly, the complexity of a task environment is contingent upon the level of uncertainty that it represents to the organization during task execution and completion. Therefore, it can be asserted that the greater the level of environmental complexity, the greater is the level of environmental uncertainty that the organization confronts and needs to manage (N obre, 2005, 2008; N obre et al., 2009a).

\section{Organizational AbILITY}

A bility is a general term concerning the capacity to act mentally, physically, financially, legally or in some other way. Cognitive ability refers specifically to mental capacity (Ree, Carretta, \& Steindl, 2002). In the context of this paper, cognitive ability involves processes and representations which support the pursuit of intelligence, autonomy, learning and knowledge management in the organization. Therefore, this paper sets cognition as the main element of organizational ability. From this viewpoint, abilities within the organization or, simply, organizational ability, involve concepts of cognition, intelligence, autonomy, learning and knowledge management. In the following subsections, this paper proposes concepts and principles of organizational cognition. It also reviews the concepts of organizational intelligence, autonomy, learning and knowledge management. In this review, the paper contributes to defining the frontiers between organizational cognition and the other organizational abilities. 


\section{Organizational Cognition}

\section{Overview}

The subject of cognition in organizations has flourished over the last fifty years in an environment of extensive and multidisciplinary research influenced by developments in general systems theory, cognitive and social psychology, artificial intelligence and cognitive science, social psychology of organizations, sociology of knowledge, organizational learning and knowledge management. Most recently, this subject has been referred to as organizational cognition (E den \& Spender, 1998; Iandoli \& Zollo, 2007; Lant \& Shapira, 2001; Nicolini, 1999; Nobre et al., 2009a, 2009b; Porac \& Thomas, 2002; Walsh, 1995).

Research on cognition in organizations has its roots in the publications of Simon (1947) on Administrative Behavior, and March and Simon (1958) on Organizations. In these publications, the organization was associated with information processing systems whose picture resembles a nexus of cognitive agents and processes organized through lateral and vertical relations. In this perspective, the organization benefits individuals and groups by extending their cognitive limitations to more advanced models of rationality (Simon, 1997a, 1997b). However, the meaning of this perspective has been separated by some researchers into two main streams: the computational and the interpretive approaches (Lant \& Shapira, 2001). The computational approach investigates the processes by which the organization manipulates information, and associates the organization with information processing machines. In this stream, the emphasis is on information and efficiency. This approach is grounded in cognitive psychology, cognitive science and artificial intelligence. The interpretive approach examines how meaning is created around information in a social context, and is related to social collectives and knowledge systems. In this stream, the focus is on knowledge and collectivities. This approach has been grounded in the sociology of knowledge, social psychology of organizations, social cognition and, most recently, in knowledge management and organizational learning, whereas the latter has also been associated with processes for creating, retaining and transferring knowledge in organizations (A rgote, 2007).

M ost of the perspectives on organizational cognition are placed somewhere in the continuum between these computational and interpretive approaches. Moreover, further research has suggested that integration of these two perspectives is the best way to make progress (Choo, 2005; Lant \& Shapira, 2001).

\section{Preliminary Concepts}

Cognition comprises the perspectives of processes and representations in the organization. On the one hand, when viewed as processes, cognition subsumes sensation, perception, attention, concept identification, categorization, knowledge representation and organization, memory, language, decision making, learning and problem solving (Nobre et al., 2009a). These cognitive processes mediate the effect of external events or stimuli on the decisions, behaviors and actions of individuals, groups and organizations in response to their experiences. The organization which is able to integrate these processes is defined as a cognitive organization, and in particular the organization which integrates the processes of sense making, knowledge creation and decision making is described as a knowing organization (Choo, 2005). In these classes of organizations, information about the environment is sensed and interpreted, and its meaning is socially constructed in the organization participants' mind. Tacit knowledge is converted to explicit knowledge and vice-versa, and individuals' knowledge is expanded to the group and organizational levels according to the knowledge creation processes of the spiral cycle presented by Ichijo and Nonaka (2006). The processes of sense making and knowledge creation provide the organization with the appropriate context for decision making, problem solving, action and learning. On the other hand, as representations, cognition is synonymous with mental images, knowledge models and cognitive maps constructed from the experiences and learning of individuals, groups and organizations. Representations play a major role in directing behavior in the absence of environmental stimuli (B rewer \& Hewstone, 2004). 


\section{Degree of Organizational Cognition}

Organizational cognition can also be associated with degree of cognition in the organization (Nobre et al., 2009a, 2009b), whereas degree of cognition can be symbolically associated with tangible and intangible measures of processes and representations. Nobre et al. (2009a), for instance, presented a case study about an international telecommunications and software business organization, in which they associated the degree of cognition in the organization with levels of organizational process maturity, capability and performance, along with organizational learning results. Qual itative analyses and quantitative measurements of the case study indicated that improvements in the levels of organization process maturity and performance were associated with improvements in the degree of organizational cognition, and also that improvements in organizational learning could be associated with improvements in organizational cognition. Similar methods have been adopted by other researchers who have associated performance and productivity gains with practices of organizational learning (A rgote, 2007).

\section{. Human vs. Organizational Cognition}

Organisms of the ecological system have evolved and improved their abilities and mechanisms for fitness and adaptation to the environment. A mong such organisms, the human being is the species that is the most likely to survive, reproduce, and continue evolving and developing. This human predominance is a particular privilege provided by the evolution of the brain, emotional and cognitive processes (Heyes \& Huber, 2000; Simon, 1983). A mong the results of such a continuous evolutionary path are their abilities to search for information, organize knowledge, make decisions, learn and solve complex problems. Humans adapt to the environment, and they also change the environment to suit their own needs. In such a continuum, humans have been transferring some of their abilities to systems, and most importantly, to organizations (Nobre, 2008). Certainly, one of the main rationales for organizing can be explained by the perspective that organizations benefit individuals and groups by extending their cognitive, physical, temporal, institutional and spatial limitations (Carley \& Gasser, 1999; Nobre, 2008).

In such a perspective, while human cognition is part of a natural system, organizational cognition is part of an artificial system because it involves the art of design (Simon, 1996). Therefore, the cognitive ability in the organization can be changed and improved through processes of organizational change and design. Hence, organizational cognition, and more precisely, the degree of cognition in the organization, is contingent upon the goals, social structure, participants, technology and environment of the organization.

\section{Ten Principles of Organizational Cognition}

Principles of organizational cognition are important if we wish to understand the roles of cognition in the organization. Initial lines on this subject were proposed by Nobre et al. (2009a), with emphasis on information processing only. This subsection contributes to the theme by restructuring and extending such principles to a more advanced perspective that subsumes computational and interpretive views of organizational cognition, where emphasis is placed on knowledge, organizational abilities and strategic context.

1) Organizational cognition is the main ability which supports agents, groups and organizations with intelligence, autonomy, learning and knowledge management.

2) Organizational cognition is associated with cognitive processes and representations in the organization. At the individual level, mental processes and representations contribute to the creation of tacit and explicit knowledge of the participants in the organization. At the group and organizational levels, processes and representations of cognition contribute to the creation of collective tacit and explicit knowledge which are expanded and crystallized in the whole organization. The knowledge creation processes can follow the spiral cycle presented by Ichijo and Nonaka (2006). 
3) The main agents of organizational cognition are the participants in the organization and the social networks they form. Agents of organizational cognition include humans and cognitive machines (Nobre, 2008; N obre et al., 2009a, 2009c).

4) Cognitive processes and representations in the organization are influenced and supported by the goals, technology and social structure of the organization.

5) The cognition in the organization is also influenced by inter-organizational processes and the environment.

6) Organizational cognition can be associated with degrees of cognition in the organization, whereas degree of cognition can be symbolically associated with tangible and intangible measures of processes and representations (Nobre et al., 2009a).

7) Research on organizational cognition is important and necessary when we decide to design organizations with higher degrees of cognition for general information processing, knowledge management, learning, decision making, problem solving and the management of environmental uncertainty.

8) The degree of organizational cognition depends on the choice of models of organizing. Therefore, the degree of organizational cognition depends on the choice of the organization's elements ${ }^{(5)}$ (goals, social structure, participants and technology) and strategy.

9) The choice of the organization's elements depends on the environment. Consequently, organization cognition (and the degree of cognition in the organization) is contingent upon the environment (and the level of environmental uncertainty).

10) Cognition is the core ability in the organization that contributes to the development of core competencies $^{(6)}$ and, consequently, provides the basis for the creation of the organization's sustainable competitive advantage ${ }^{(7)}$.

\section{Organizational Intelligence}

Intelligence is a general mental ability (Schmidt \& Hunter, 2000) that depends on rational and emotional processes (Goleman, 1994). Rational process or rationality is the ability to follow procedures for decision making and problem solving in the pursuit of goals (Simon, 1997a). When rational processes lead individuals to satisfactory (satisfice) outcomes, rationality can be associated with intelligence. Emotional process ${ }^{(8)}$ is less procedural than rationality and it is less purposeful in the context of achieving goals. However, researchers have shown that emotions play an important part in motivating, directing and regulating actions in the service of goal pursuit (Bagozzi, 1998; K eltner \& Gross, 1999; K eltner \& Haidt, 1999). When emotional processes lead individuals to excel in life $e^{(9)}$, emotion can be associated with intelligence. Complementarily, while emotion influences cognitive processes such as attention, learning, decision making and problem solving (Goleman, 1994), cognition is in the service of emotion when interpreting stimuli (Plutchik, 1982) and regulating emotional processes and states. Therefore, intelligence and, in particular, intelligent behavior depend on cognitive and emotional processes.

Organizational intelligence can also be associated with degrees of intelligence in the organization. It has similar principles to organizational cognition. However, while organizational cognition is associated with cognitive processes and representations in the organization, organizational intelligence is associated with the degree to which the organization satisfies - satisfice (Simon, 1997b) - its goals and sub-goals. Therefore, the greater the degree of cognition in the organization, the greater is its chance to exhibit intelligent behavior (N obre et al., 2009a, 2009b). 


\section{Organizational Autonomy}

A utonomy is the ability of individuals, groups and organizations to act through the use of cognition. Autonomous organisms are continuously in pursuit of intellectual independence and therefore are continuously attempting to improve their cognitive abilities. Like organizational cognition and intelligence, organizational autonomy is a matter of degree. The degree of autonomy of individuals, groups and organizations improves as much as they interact with the environment by capturing, processing, creating, storing, exchanging and managing new resources. From this viewpoint, organizations with higher degrees of cognition have higher degrees of autonomy (N obre et al., 2009a, 2009b).

\section{Organizational Learning}

Organizational learning has been associated with the creation and management of knowledge in organizations (Argote, 2007; Dierkes, Antal, Child, \& Nonaka, 2003). In psychology research, learning is the process of making changes in the individual's mind and behavior through experiences along with cognitive, emotional and environmental influences (B ernstein, Penner, Clarke-Stewart, \& Roy, 2008; Illeris, 2007; Lefrançoies, 1995; M insky, 1986; Reed, 1988). In such a process, learning involves acquiring, enhancing or making changes in one's knowledge, skills, values and world views. This paper supports this definition and puts forward the perspective that organizational learning is the process of making changes in the organization's elements (goals, social structure, technology and participants) and behavior through experience, cognition, emotion and environmental influences for the benefit of the organization. Such a perspective implies relations on the effect of organizational learning on organizational cognition and vice-versa. On one hand, it is plausible to say that organizational learning affects organizational cognition and, more specifically, the degree of organizational cognition by changing cognitive processes and representations in the organization. On the other hand, it is also plausible to state that organizational learning depends on organizational cognition and, more specifically, on cognitive processes and representations for the corroboration of change and for the creation and management of knowledge in the organization. The process of change in the organization follows mechanisms and models which are mostly based on principles of feedback control, adaptive and learning systems that originated in the broad fields of cybernetics and general systems theory (A shby, 1968; B ertalanffy, 1968; Buckley, 1968; W iener, 1961). W ell-known models of organizational learning include single-loop and double-loop types (A rgyris \& Schön, 1978) along with meta-learning, the concept of which was introduced by Biggs (1985) to describe the state of being aware of and taking control of one's own learning. Further studies on the concept of metalearning and its distinction from deuteron and planned-learning are discussed in V isser (2007); and the use of organizational meta-learning for the construct of dynamic core competencies is presented by Lei, Hitt and Bettis (1996).

In such a view, cognition is what provides individuals, groups and organizations with the ability to learn. Therefore, organizations with higher degrees of cognition have greater capacity or higher degrees of learning ( $N$ obre et al., 2009a).

\section{Knowledge Management}

Different views and definitions of knowledge can lead to distinct concepts of knowledge management. The perspective of this paper is that knowledge primarily emerges from the information possessed and personalized in the minds of individuals (Alavi \& Leidner, 2001). Moreover, knowledge is classified into epistemological and ontological dimensions (Ichijo \& Nonaka, 2006). From these preliminaries, this paper defines that $K$ nowledge $M$ anagement $(K M)$ in organizations involves a set of practices and socially enacted processes for (1) creation, including renovation and conversion (from tacit to explicit, and from explicit to tacit knowledge), (2) storage and retrieval, (3) transfer, exchange, and distribution and (4) application of knowledge, through individuals, groups and organizational processes and practices for the benefit of the organization. While individuals are the 
main agents of knowledge creation, the organization is the agency which supports them with the necessary elements and conditions for the production, application and expansion of their knowledge to the group, organizational and inter-organizational ontological levels (Takeuchi \& Nonaka, 2004). The subject of knowledge management overlaps with organizational cognition since both fields share studies on processes of creation, organization and management of knowledge. From this point of view, organizational cognition supports knowledge management with cognitive processes that include concept formation, categorization, knowledge organization and representation, memory and learning, to name a few. Therefore, organizations with higher degrees of cognition have greater capacity or degree of knowledge management.

However, more recently, the field of knowledge management was introduced by some researchers as a branch of the broad areas of strategic management and resource based view of the firm. In such a strategic context, knowledge is defined as the main strategic asset in a knowledge-based view of the firm (Grant, 1996; Ichijo \& Nonaka, 2006; Oliveira, 1999; Spender, 1996a, 1996b). From such a new perspective, research on knowledge management has expanded its frontiers and contributions, and it has also received a more pragmatic place in organizational studies. Therefore, inspired by these advancements in knowledge management, this paper suggests that further investigations can extend the fields of organizational cognition and organizational ability toward new contexts of cognition and ability-based views of the firm.

\section{COGNITION AND THE CONTROL OF UNCERTAINTY}

The definitions and propositions introduced in this section are mostly grounded in the contingency theories (Burns \& Stalker, 1994; Donaldson, 2001; Galbraith, 1977; Lawrence, 2000). However, this paper differs from and extends these works by introducing cognition as the main ability to effectively control environmental uncertainty. On the one hand, uncertainty is defined as the state variable, and, on the other hand, cognition is defined as the control variable ${ }^{(10)}$. Therefore, this paper implies that uncertainty can be influenced, controlled, governed and reduced in some extent by the cognitive abilities in the organization.

\section{Relations on Cognition and Uncertainty}

This section introduces relations between organizational cognition and environmental uncertainty are derived from the proposed concepts of Relative L evel of Environmental Uncertainty and Relative Degree of Organizational Cognition.

\section{- Relative Level of Environmental Uncertainty}

Definition 1: The Relative Level of Environmental Uncertainty $\left(R_{U}\right)$ is defined by the proportional relation between Level of Environmental Uncertainty $\left(E_{U}\right)$ and Degree of Organizational Cognition $\left(O_{c}\right)$, i.e., $R_{U}=E_{U} / O_{c}$.

Definition (1) indicates that the Relative Level of Environmental Uncertainty $\left(R_{U}\right)$ varies according to four distinct circumstances or causalities:

(i) $R_{U}$ reduces when there is a growth in $0_{c}$, for a given $E_{U}$.

(ii) $R_{U}$ reduces when there is a reduction in $E_{U}$, for a given $0_{C}$.

(iii) $R_{U}$ grows when there is a reduction in $0_{c}$, for a given $E_{U}$.

(iv) $R_{U}$ grows when there is a growth in $E_{U}$, for a given $0_{C}$. 


\section{. Relative Degree of Organizational Cognition}

Definition 2: The Relative Degree of Organizational Cognition $\left(R_{c}\right)$ is defined by the proportional relation between Degree of Organizational Cognition $\left(O_{C}\right)$ and Level of Environmental Uncertainty $\left(E_{u}\right)$, i.e., $R_{c}=0_{c} / E_{U}$.

Similarly, definition (2) indicates that the Relative Degree of Organizational Cognition $\left(R_{c}\right)$ varies according to four distinct circumstances or causal ities:

(a) $R_{c}$ grows when there is a growth in $\mathrm{O}_{c}$, for a given $\mathrm{E}_{U}$.

(b) $R_{c}$ grows when there is a reduction in $E_{U}$, for a given $O_{C}$.

(c) $R_{c}$ reduces when there is a reduction in $\mathrm{O}_{c}$, for a given $\mathrm{E}_{U}$.

(d) $R_{C}$ reduces when there is a growth in $E_{U}$, for a given $0_{C}$.

\section{A nalyses of the Relations}

Definitions (1) and (2), and more specifically, their respective causalities (i) to (iv), and (a) to (d), suggest a total of eight alternatives of strategy which can lead to four possible goals: the reduction or the growth in the Relative Level of Environmental Uncertainty $\left(R_{u}\right)$, and the reduction or the growth in the Relative Degree of Organizational Cognition $\left(R_{c}\right)$. As this paper focuses on organizational cognition, it selects strategies (i) and (a). Both strategies increase the Degree of Organizational Cognition $\left(\mathrm{O}_{C}\right)$ in order to reduce the Relative Level of Environmental Uncertainty $\left(R_{u}\right)$ and to increase the Relative Degree of Organizational Cognition $\left(R_{C}\right)$.

From these conceptualizations, this paper proposes that:

Proposition 1: The higher the Degree of Organizational Cognition $\left(\mathrm{O}_{\mathrm{C}}\right)$, the lower is the Relative Level of Environmental Uncertainty $\left(R_{U}\right)$, and the higher is the Relative Degree of Organizational Cognition $\left(R_{C}\right)$.

Proposition (1) suggests that, while the environment influences the organization through information and uncertainty, to some extent the organization can control the environment through its cognitive abilities along with intelligence, autonomy, learning and knowledge management.

\section{FuzZY MODEl OF COMPLEX ORgANIZATIONAL SYSTEMS}

This section contributes mathematical definitions and fuzzy models of organizational ability, environmental ability, relational ability between the organization and the environment, and networks of organizations.

\section{Model of Organizational Ability}

Definition 3: The organization is a special type of dynamic system ${ }^{(11)}$ characterized by a level of ability $A_{L}$ which is contingent upon its degree of cognition $C_{d}$, intelligence $I_{d}$, autonomy $A_{d}$, learning $L_{d}$, and knowledge management $K M_{d}$.

Axiom 1: Considers that $A_{L}$ is the level of ability of an organization $O_{s}$ and that $C_{d}, I_{d}, A_{d}, L_{d}$ and $K M_{d}$ are its degrees of cognition, intelligence, autonomy, learning and knowledge management, respectively. M oreover, it assumes that $A_{L}$ can be characterized by a function $g$ of parameters $C C_{d}, I_{d}$, $A_{d}, L_{d}$ and $K M_{d}$ : 


$$
A_{L} \sim g\left(C_{d}, I_{d}, A_{d}, L_{d}, K M_{d}\right) \mid 1 \cdot A_{L}, C_{d}, I_{d}, A_{d}, L_{d}, K M_{d} \cdot 0
$$

$C_{d}, I_{d}, A_{d}, L_{d}$ and $K M_{d}$ are defined in the interval $[0,1]$ since they can be characterized by using the concepts of fuzzy sets and membership functions ${ }^{(12)}$ (Zadeh, 1965). The application of the fuzzy sets theory is encouraged to this definition of organizations because ability, cognition, intelligence, autonomy, learning and knowledge management are vague and loose concepts in the sense defined by Black $(1937,1963)$, and they also are fuzzy concepts in the way defined by Zadeh $(1965,1973)$. Therefore, $C_{d}, I_{d}, A_{d}, L_{d}$ and $K M_{d}$ can be represented as matters of degree in the continuous interval $[0,1]$.

Axiom 2: In this way, let us define an organization $0_{s}$ denoted here by an object $u$ belonging to an universe of discourse $U$, which contains the all classes of organizations, i.e., $\left(u_{i} \in U \mid \mathbf{i}=1, \ldots, N\right)$, for $i$ integer.

Axiom 3: Let us also define the level of ability $A_{L}$, and the degrees of cognition $C_{d}$, intelligence $I_{d}$, autonomy $A_{d}$, learning $L_{d}$ and knowledge management $K M_{d}$ as fuzzy sets with their respective membership functions denoted by $\mu_{A L}(u), \mu_{C d}(u), \mu_{I d}(u), \mu_{A_{d}}(u), \mu_{L d}(u), \mu_{K M d}(u) \in[0,1]$, i.e.:

$$
\begin{aligned}
& A_{L}=\left\{u \mid \mu_{A_{L}}(u) \in[0,1], u \in U\right\} \\
& C_{d}=\left\{u \mid \mu_{C_{d}}(u) \in[0,1], u \in U\right\} \\
& I_{d}=\left\{u \mid \mu_{I_{d}}(u) \in[0,1], u \in U\right\} \\
& A_{d}=\left\{u \mid \mu_{A_{d}}(u) \in[0,1], u \in U\right\} \\
& L_{d}=\left\{u \mid \mu_{L_{d}}(u) \in[0,1], u \in U\right\} \\
& K_{d} M_{d}=\left\{u \mid \mu_{K M_{d}}(u) \in[0,1], u \in U\right\}
\end{aligned}
$$

Therefore, $\mathrm{O}_{\mathrm{s}}$ can assume degrees of ability, intelligence, cognition, autonomy, learning and knowledge management respectively, where such degrees can be interpreted as degrees of compatibility or membership of $O_{s}$ of the respective fuzzy sets of $C_{d}, I_{d}, A_{d}, L_{d}$ and $K M_{d}$.

From equation (1), it can be stated that:

Definition 4: The level of ability $A_{L}$ is a function $g$ which can be represented by a t-norm $\bullet$ or an $\mathrm{s}$ norm . (Dubois \& Prade, 1985):

$$
\begin{aligned}
& A_{L}(\cdot)=\left\{u \mid \mu_{A_{L}}(u)=\mu_{\left(C_{d} \cdot I_{d} \cdot A_{d} \cdot L_{d} \cdot K M_{d}\right)} \in[0,1], u \in U\right\} \\
& A_{L}(\cdot)=\left\{u \mid \mu_{A L}(u)=\mu_{\left(C_{d} \cdot I_{d} \cdot A_{d} \cdot L d \cdot K M_{d}\right)} \in[0,1], u \in U\right\}
\end{aligned}
$$

where the t-norm - and s-norm . can be viewed as respective representations of intersection and union operations in fuzzy sets (Zadeh, 1973). Therefore, equations (8) and (9) denote that $A_{L}$ is a fuzzy set which membership function is the result of the intersection or union of $C_{d}, I_{d}, A_{d}, L_{d}$ and $K M_{d}$.

\section{Model of Environmental Ability}

This subsection is about the environment $e$, and it subsumes relations $R_{e}$ between the organization $\mathrm{O}_{s}$ and the environment $\mathrm{e}$.

Axiom 4: Let us consider an organization $O_{s 1}$ with relations $R_{e 1}$ to an environment $e_{1},\left(O_{s 1} \cdot R_{e 1}\right.$ • $\left.e_{1}\right)$, which has relations $R_{e_{2}}$ to another environment $e_{2},\left(e_{1} \cdot R_{e_{2}} \cdot e_{2}\right)$. Therefore, a generic environment $e_{n}$ of an organization $0_{s_{n}}$ forms relations $R_{e(n+1)}$ to an environment $e_{(n+1),}\left(e_{n} \cdot R_{e(n+1)} \cdot\right.$ $\left.e_{(n+1)}\right)$, where $n$ is an integer. 
Axiom 5: Let us define a network $N_{E}$ constituted by $(n+1)$ organizations $O_{s(i=1, \ldots, n+1)}$. Let us also define the organization $O_{s 2}$ as the environment of $O_{s 1}$ with relations $R_{e 1}$ between them, and $O_{s 3}$ as the environment of $O_{s 2}$ with relations $R_{e_{2}}$. Therefore, it can be derived that $O_{s(n+1)}$ is the environment of $O_{s n}$ with relations $R_{e n}$ between them: $\left(O_{s_{n}} \cdot R_{e n} \cdot O_{s(n+1)}\right)$.

Axioms (4) and (5) also imply that an environment is a relative concept that depends on the perspective of our analysis on a map of networks of organizations. This means that the roles of $e$ and $0_{s}$ may be exchanged since an environment e can represent an organization $0_{s}$, and vice-versa, according to the perspective that someone has of the map of networks of organizations. Therefore:

Definition 5: Similarly to $0_{s}$, definitions (3) and (4) also apply to the environment e, where $0_{s}$ is replaced with e.

\section{Relational Ability between the Organization and the Environment}

This subsection complements the definitions of the organization $O_{s}$ and the environment e by introducing different types of relations $R_{e}$ which can exist between them. It borrows from and adapts the approach to the analysis of ecological dynamics presented by Boulding (1978) in order to describe the diversity of relations $R_{\mathrm{e}}$.

Axiom 6: Lets us assume an organization $0_{s}(t)$ with a set of state variables denoted by $\mathbf{X}(t)$, where $t$ denotes time. Additionally, let us define the organization's performance $\mathrm{P}_{0_{s}(t)}$ as a measure of its efficacy and efficiency which are dependent on the behavior of $\mathbf{X}(\mathrm{t})$.

Axiom 7: Similarly, let us consider an environment $e(t)$ with state variables $\mathbf{Y}(\mathrm{t})$ and with performance denoted by $P_{e(t)}$, which holds the same assumptions given to $P_{{ }_{0 s}(t)}$.

Axiom 8: L et us assume that $O_{s}(t)$ can affect $e(t)$ in three ways. First, $O_{s}(t)$ may affect $e(t)$ favorably, and hence the relation $R_{e}(t)$ is cooperative. $A$ rise in $P_{0_{s}(t)}$ will increase $P_{e(t)}\left(i . e .\right.$, if $P_{0_{s}(t)} \bullet$ then $\left.P_{e(t)} \bullet\right)$. Second, the relationship $R_{e}(t)$ may be competitive. In this case, a rise in $P_{o_{s}(t)}$ leads to a decline in $P_{e(t)}$, and a fall in $\mathrm{P}_{0_{s}(t)}$ causes a rise in $\mathrm{P}_{\mathrm{e}(t)}$ (i.e., if $\mathrm{P}_{\mathrm{Os}_{s}(t)} \bullet$ then $\mathrm{P}_{\mathrm{e}(t)} \bullet$, and if $\mathrm{P}_{\mathrm{O}_{s}(\mathrm{t})} \bullet$ then $\mathrm{P}_{\mathrm{e}(t)} \bullet$ ). Third, $\mathrm{P}_{\mathrm{e}(\mathrm{t})}$ may have no dependence on $\mathrm{P}_{0_{s}(t)}$ and therefore a rise or a fall in $\mathrm{P}_{0_{s}(t)}$ may have no effect on $\mathrm{P}_{\text {e(t) }}$ (i.e., if either $\mathrm{P}_{0 \mathrm{~s}(t)} \bullet$ or $\bullet$ then $\mathrm{P}_{\mathrm{e}(\mathrm{t})}(0)$ ).

Similar relations can be postulated for the influence of e(t) on $0_{s}(t)$. In this case, new representations have to be derived. Therefore:

Axiom 9: $L$ et us denote $R_{\left(e \cdot 0_{s}\right)}$ as the relations to the effect of e(t) on $O_{s}(t)$, and $R_{\left(0_{s} \cdot \text { e) }\right.}$ as the relations of $\mathrm{O}_{\mathrm{s}}(\mathrm{t})$ on $\mathrm{e}(\mathrm{t})$.

The results of all possible combinations are given in Table 1, while Table 2 describes the results of such combinations.

Definition 6: Relations $R_{e}$ are dynamical systems whose attributes can change over time. Examples of attributes applicable to these relations are competition and cooperation. $R_{e}$ does not guarantee bilateral properties, i.e., the types of relations created from $O_{s}(t)$ to $e(t)$ as given by $R_{\left(0_{s}\right.}$ e e) may differ from the relations of $R_{\left(e \cdot 0_{s}\right)}$. M oreover, definitions (3) and (4) also apply to the concept of relations $R_{e}$ between $\mathrm{O}_{\mathrm{s}}$ and $\mathrm{e}$. 
Table 1

Classes of Relations $R_{\mathrm{e}}(t)$

\begin{tabular}{|c|c|c|c|}
\hline$\overbrace{\mathrm{R}_{(\mathrm{e} \cdot 0 \mathrm{~s})}}^{\mathrm{R}_{\left(\mathrm{O}_{\mathrm{s}} \cdot \mathrm{e}\right)}}$ & $\begin{array}{l}\text { Cooperative } \\
\mathrm{P}_{\mathrm{O}_{\mathrm{s}}}(\mathrm{t}) \cdot \mathrm{Pe}(\mathrm{t}) \cdot\end{array}$ & $\begin{array}{l}\text { Competitive } \\
\mathrm{P}_{\mathrm{O}_{\mathrm{s}}}(\mathrm{t}) \cdot \mathrm{Pe}(\mathrm{t}) \bullet\end{array}$ & $\begin{array}{c}\text { Independent } \\
\mathrm{P}_{\mathrm{Os}_{s}}(\mathrm{t}) \cdot \mathrm{Pe}(\mathrm{t})(0)\end{array}$ \\
\hline $\begin{array}{l}\text { Cooperative } \\
\mathrm{P}_{\mathrm{e}(\mathrm{t})} \cdot \mathrm{P}_{\mathrm{O}_{\mathrm{s}}}(\mathrm{t}) \cdot\end{array}$ & 1 & 4 & 7 \\
\hline $\begin{array}{l}\text { Competitive } \\
P_{e(t)} \bullet P_{O_{s}}(t) \bullet\end{array}$ & 2 & 5 & 8 \\
\hline $\begin{array}{l}\text { Independent } \\
\mathrm{P}_{\mathrm{e}(\mathrm{t})} \cdot \mathrm{P}_{\mathrm{O}_{\mathrm{s}}}(\mathrm{t})(0)\end{array}$ & 3 & 6 & 9 \\
\hline
\end{tabular}

Table 2

\section{Analysis of R elations $R_{e}(t)$}

\begin{tabular}{cc}
\hline Cases & Interpretation \\
1 & $0 s(t)$ contributes to $e(t)$ and $e(t)$ contributes to $0 s(t)$ \\
2 & $0 s(t)$ contributes to $e(t)$ but $e(t)$ harms $0 s(t)$ \\
3 & $0 s(t)$ contributes to $e(t)$ but $e(t)$ has no effect on $0 s(t)$ \\
4 & $0 s(t)$ harms $e(t)$ but $e(t)$ contributes to $0 s(t)$ \\
5 & $0 s(t)$ harms $e(t)$ and $e(t)$ harms $0 s(t)$ \\
6 & $0 s(t)$ harms $e(t)$ but $e(t)$ has no effect on $0 s(t)$ \\
7 & $0 s(t)$ has no effect on $e(t)$ but $e(t)$ contributes to $0 s(t)$ \\
8 & $0 s(t)$ has no effect on $e(t)$ but $e(t)$ harms $0 s(t)$ \\
9 & $0 s(t)$ does not affect $e(t)$ and $e(t)$ does not affect $0 s(t)$ \\
\hline
\end{tabular}

\section{Networks of Organizations}

An important result derived from axiom (5) and definition (5) is the concept of networks of organizations as outlined here.

Definition 7: A network of $(n+1)$ organizations $0_{s(i=1, \ldots, n+1)}$ is a dynamic system denoted by $N_{E}(t)$ whose relations $R_{e(i=1, \ldots, n+1)}$ change over time.

\section{CONCLUSIONS}

This paper proposed a new contingency view of the organization that contributed through two complementary perspectives. First, it proposed cognition as a function which acts as the main mediator between the organization and the environment. Second, it introduced cognition as the main organizational ability that supports individuals, groups and organizations with intelligence, autonomy, learning and knowledge management; in such a perspective, cognition can be viewed as the core 
resource in the service of the organization. Both perspectives, the mediation and the core organizational resource views, suggest that cognition is a source of reduction of environmental complexity and uncertainty. From these pictures, this work emphasized the organization in the pursuit of high degrees of organizational cognition in order to manage high levels of environmental complexity and uncertainty.

In these perspectives, this work presented four important contributions about organizational cognition. First, it proposed ten principles about organizational cognition that unify concepts of computational and interpretive approaches. These principles contributed by introducing organizational cognition into the strategic domain, defining cognition as an important strategic ability which supports individuals, groups and organizations with intelligence, autonomy, learning and knowledge management, by introducing the notion of degree of organizational cognition and defining its contingency upon organization design and the environment. They also contributed by defining organizational cognition as a source of development of core competencies and the creation of the organization's competitive advantage. Second, the article contributed by outlining and explaining the frontiers and complementary relations between organizational cognition and the concepts of organizational intelligence, autonomy, learning and knowledge management and, therefore, it suggested the basis of a new perspective on organizational abilities. Third, it proposed relations between organizational cognition and environmental uncertainty. This perspective contributed by introducing cognition as the main ability in the service of the organization and, more specifically, for the control, regulation and reduction of the level of environmental uncertainty. As a result of the analysis, this research proposed that, while the environment influences the organization through information and uncertainty, to some extent the organization can control the environment through its cognitive abilities along with intelligence, autonomy, learning and knowledge management. Fourth, it presented a model of the organization as a set of fuzzy abilities. This model contributes to the analyses of the organization and the environment through the new perspective of organizational abilities.

\section{Signpost to the Future}

While the characteristics of the elements of the organization will change, evolve and develop continuously towards higher levels of cognition and complexity, the purpose for the existence of the organization will remain the same or will not change in the same proportion of its elements (Nobre, $2005,2008)$. The former part, which is concerned with the elements of the organization, will move towards high levels of automation, and this will include machines with high degrees of cognition, mainly in those areas in the upper layers and levels of the organization; and thus they will provide organizations with more capabilities of computational capacity along with knowledge and uncertainty management. Therefore, new organizations of this kind will be able to operate in and manage higher levels of environmental complexity and uncertainty than organizations of today. These transformations towards new organizations will have implications for society, and this is a topic for further research (Nobre et al., 2009a, 2009b, 2009c; N obre et al., 2010). The latter part, which is concerned with the purpose and the existence of organizations, will remain the same and will certainly not change to the same extent in the evolutions of organizational elements. This is because the individual motives and the organizational goals which are pursued by humankind will not change over time into the political, economic and social facets of this society.

One day, perhaps not so far into the $21^{\text {st }}$ century, worldwide organizations and their executives will have the ability to perceive, sense, decide and act based on new models of organizing and management thought which are grounded in concepts of systemic sustainability, and these new models will require the reconciliation of environmental, social and economic demands - the three pillars of sustainability ${ }^{(13)}$. It is in such a new context that organizations and their participants will be challenged to decide whether they are ready to create competitive advantage without affecting the balance and equilibrium of such a triad. It raises the question of the endurance and survival of the human species. 


\section{NOTES}

${ }^{1}$ The subject of emotions in organizations is left for further research. Perspectives about this topic can be found in Bagozzi, R. P., B aumgartner, H., \& Pieters, R. (1998). Goal-directed emotions. Cognition and Emotion, 12(1), 1-26; Fineman, S. (1993). E motions in Organizations. London: SA GE Publications; K eltner and Gross, (1999); Keltner and Haidt, (1999); Plutchik, (1982) and Scherer, K. R. (1982). Emotion as a process: function, origin, and regulation. Social Science Information, 21(4-5), 555-570.

2 The organizations in this paper satisfy the concept of open-rational systems (Nobre, 2005; Scott, 1998) and also the perspective of economic organizations (M ilgrom, P. \& Roberts, J. (1992) Economics, organizations \& management. N ew J ersey: Prentice Hall.). This type of organization integrates resources, core competencies, participants, technology and goals into a coordinative social structure in order to cope with the environment. They are formal organizations that pursue specific goals and that produce goods and services.

${ }^{3}$ The environment includes information, consumers and stakeholders, other organizations such as buyers and suppliers, networks of organizations, institutions, market regulators, the whole economy, cultural values and natural resources (M ilgrom \& Roberts, 1992).

${ }^{4}$ Information has quantitative and semantic domains. The quantitative domain refers to the volume or amount of information, and the semantic represents the meaning of the information that the organization needs to process, to interpret and to manage. In this perspective, the semantic domain also includes the syntax that regards the relationship among the parts of the information.

${ }^{5}$ The elements of the organization include goals, social structure, technology and the participants in the organization (Scott, 1998). Moreover, the organization exists in a physical, technological, cultural and social environment with which the organization interacts (Scott, 1998). Participants are the agents who act in the name of the organization and include humans and cognitive machines (Nobre, 2008, Nobre et al., 2009a, 2009c). Technology expands what organizations can do and it supports the connection of the organization to the environment. Goals and sub-goals are what organizations aim to achieve in order to satisfy people's desires. Social structure refers to the standards and regularized aspects of the relationships existing among the participants in the organization and comprises the normative and behavioral parts (Nobre et al., 2009a; Scott, 1998).

${ }^{6}$ Core competencies are capabilities which are valuable and unique from a customer's point of view, and also inimitable and non-substitutable from a competitor's point of view (Prahalad, C. K., \& Hamel, G. (1990). The core competence of the corporation. Harvard Business Review, 68(3), 79-91; Hitt, M. A., Ireland, R. D., \& Hoskisson, R. E. (2008). Strategic management: competitiveness and globalization, concepts and cases. Canada: South-Western College Pub.). Core competencies can represent a set of tacit and collective knowledge which is developed through learning processes and which provides the organization with particular strengths and superior value relative to other organizations. These are sources of innovation, customer benefits and sustainable competitive advantage (L ei et al., 1996; Oliveira, 1999).

${ }^{7}$ Competitive advantage is a position that a firm occupies in its competitive environment and it also represents the organization's capability to create superior value for its customers and superior profits for itself (Porter, M. E. (1998). Competitive advantage: creating and sustaining superior performance. New York: Free Press). The organization's competitive advantage becomes sustainable when its value evolves with a basis on the strategic resources management along with the development of dynamic core competencies (L ei et al., 1996).

${ }^{8}$ Emotional process is synonymous with emotion when this latter is viewed as processes, rather than emotional states (Scherer, 1982). Examples of emotional and affective states include feeling, happiness, sadness, anxiety, guilt, fear, jealous, angry, love, etc.

9 The ability to excel in life depends on self-awareness, self-discipline, self-motivation, impulse control, persistence, empathy, zeal, social deftness, trustworthiness and tal ent for collaboration, among other skills.

${ }^{10} \mathrm{~B}$ riefly, state variables describe the state, position, condition, trajectory, behavior of a system. Control variables influence state variables and are used to govern the state or behavior of a system. In this paper, variables mean changes in the concepts, states, values, processes, structures or forms of something

${ }^{11}$ A dynamic system has time-varying interactions (Forrester, J. W. (1961). Industrial dynamics. Cambridge, M A: The M IT Press). This paper views systems as defined in (Bunge, M., \& Ardila, R. (1987); Hall, A. D. \& Fagen, R. E. (1956). Definition of system. In W. Buckley (Ed.), Modern systems research for the behavioral scientist (pp. 81-92). Chicago: A ldine Publishing Company). Additionally, it considers the organization as a system with a memory; i.e., given the state of an organization $O_{s}$ at a discrete time $k$, then it is assumed that $0_{s}(k+1)=0_{s}(k)+0_{s}(k-1)$.

${ }^{12}$ Fuzzy sets are classes whose boundaries are not clearly defined and hence the transition from membership to nonmembership of their elements is gradual rather than abrupt. Examples include the classes of short and tall, young and old and poor and rich people. Therefore, the elements $v$ of a fuzzy set $A$ assume degrees of membership $\mu_{A}(v)$ in $A$ whose values can vary gradually from 0 to 1 , in a discrete or continuous way, i.e., $A=\left\{v \mid \mu_{A}(v) \in[0,1], v \in V\right\}$, where $V$ denotes the universe of $v$. In its broader sense, the fuzzy sets theory provides a mathematical background for the representation of information in the approaches to fuzzy logic, computing with words and computational theory of perceptions (Zadeh, 1973, Zadeh, L. A . 
(1996). Fuzzy logic = computing with words. IEEE Transactions on Fuzzy Systems, 4(2), 103-111, Zadeh, L. A. (1999). From computing with numbers to computing with words - from manipulation of measurements to manipulation of perceptions. IEE E Transactions on Circuits and Systems, 45(1), 105-119 and Zadeh, L. A. (2001). A new direction in Al: toward a computational theory of perceptions. Al Magazine, 22(1), 73-84).

${ }^{13}$ The three pillars were defined by The U nited N ations General A ssembly during the W orld Summit Outcome in 2005.

\section{REFERENCES}

Alavi, M., \& Leidner, D. E. (2001). Knowledge management and knowledge management systems: conceptual foundations and research issues. MIS Quarterly, 25(1), 107-136.

Argote, L. (2007). Organizational learning: creating, retaining and transferring knowledge. New Y ork: Springer.

A rgyris, C., \& Schön, D. A . (1978). Organizational learning: a theory of action perspective. Reading, M A : A ddison-W esley.

A shby, W. R. (1968). Principles of the self-organizing system. In W. Buckley (Ed.), M odern systems research for the behavioral scientist (pp. 108-118). Chicago: A Idine Publishing Company.

Bagozzi, R. P., Baumgartner, H., \& Pieters, R. (1998). Goal-directed emotions. Cognition and E motion, 12(1), 1-26.

Bernstein, D. A ., Penner, L. A ., Clarke-Stewart, A ., \& R oy, E. J. (2008). Psychology (8th ed.). Boston: Houghton M ifflin Company.

B ertalanffy, L., V on (1968). General system theory: foundations, development, and applications. New Y ork: Allen Lane.

Biggs, J. B. (1985). The role of meta-learning in study process. British Journal of Educational Psychology, 55, 185-212.

Black, M. (1937). V agueness: an exercise to logical analysis. Philosophy of Science, 4(4), 427-455.

Black, M . (1963). Reasoning with loose concepts. Dialogue, 2, 1-12.

Boulding, K. E. (1956). General systems theory: the skeleton of science. Management Science, 2(3), 197-208.

Boulding, K. E. (1978). Ecodynamics: a new theory of societal evolution. B everly Hills: SA GE.

Brewer, M. B., \& Hewstone, M. (2004). Social cognition. Oxford, UK and Malden, M A : Blackwell Publishing.

Buckley, W. (1968). Modern systems research for the behavioral scientist. Chicago: Aldine Publishing Company.

Bunge, M ., \& A rdila, R. (1987). P hilosophy of psychology. New Y ork: Springer-V erlag.

Burns, T., \& Stalker, G. M . (1994). The management of innovation. Oxford: Oxford U niversity Press.

Carley, K. M., \& Gasser, L. (1999). Computational organizational theory. In G. Weiss (Ed.), Multiagent systems: a modern approach to distributed artificial intelligence (pp. 299-330). Cambridge, MA : The MIT Press.

Choo, C. W. (2005). The knowing organization: how organizations use information to construct 
meaning, create knowledge, and make decisions (2nd ed.). Oxford: Oxford U niversity Press.

Dierkes, M., A ntal, A. B ., Child, J., \& N onaka, I. (2003). Handbook of organizational learning and knowledge. Oxford: Oxford U niversity Press.

Donaldson, L. (2001). The contingency theory of organizations. Thousand Oaks, CA: Sage.

Dubois, D., \& Prade, H. (1985). A review of fuzzy set aggregation connectives. Information Sciences, $36(1-2), 85-121$.

Ducan, R. B. (1972). Characteristics of organizational environments and perceived environmental uncertainty. Administrative Science Quarterly, 17(3), 313-327.

Eden, C., \& Spender, J. C. (1998). Managerial and organizational cognition: theory, methods and research. London: Sage.

Galbraith, J. R. (1973). D esigning complex organizations. R eading, M A : A ddison-W esley.

Galbraith, J. R. (1974). Organization design: an information processing view. Interfaces, 4(3), 28-36.

Galbraith, J. R. (1977). O rganization design. Reading, M A : A ddison-W esley.

Galbraith, J. R. (2002). Designing organizations - an executive guide to strategy, structure, and process. San Francisco: J ossey-B ass.

Goleman, D. (1994). Emotional intelligence: why it can matter more than IQ. New York: Bantam B ooks.

Grant, R. M . (1996). Toward a knowledge-based theory of the firm. Strategic Management J ournal, 17(Special Issue), 109-122.

Heyes, C., \& Huber, L. (2000). The evolution of cognition. Cambridge, M A: M IT Press.

Iandoli, L., \& Zollo, G. (2007). Organizational cognition and learning: building systems for the learning organization. Hershey, PA : Information Science Publishing.

Ichijo, K., \& Nonaka, I. (2006). Knowledge creation and management: new challenges for managers. Oxford: Oxford University Press.

Illeris, K. (2007). How we learn: learning and non-learning in school and beyond. London: Routledge.

K eltner, D., \& Gross, J. (1999). Functional accounts of emotions. Cognition and Emotion, 13(5), 467480.

K eltner, D., \& Haidt, H. (1999). Social functions of emotions at four levels of analysis. Cognition and Emotion, 13(5), 505-521.

K lir, G. J., \& Folger, T. A. 1988). F uzzy sets, uncertainty, and information. New Jersey: Prentice Hall.

Lant, T. K., \& Shapira, Z. (2001). Organizational cognition: computation and interpretation. London: L awrence Erlbaum A ssociates.

Lawrence, P. R. (2000). The contingency approach to organizational design. In R. T. Golembiewski (Ed.), Handbook of organizational behavior (2nd ed., pp. 7-18). B oca Raton, FL: CRC Press.

Lefrançoies, G. (1995). Theories of human learning. Pacific Grove, CA: Brooks Cole Publishing Company. 
Lei, D., Hitt, M. A., \& Bettis, R. (1996). Dynamic core competences through meta-learning and strategic context. J ournal of M anagement, 22(4), 549-569.

M arch, J. G., \& Simon, H. A . (1958). Organizations. New Y ork: J ohn Wiley \& Sons, Inc.

M insky, M . (1986). The society of mind. L ondon: Picador.

Nicolini, D. (1999). Comparing methods for mapping organizational cognition. Organization Studies, 20(5), 833-860.

Nobre, F. S. (2005). On cognitive machines in organizations. PhD Thesis, University of Birmingham, Birmingham, UK, England.

Nobre, F. S. (2008). Cognitive machines in organizations: concepts and implications. Germany: VDM -V erlag Publishing.

Nobre, F. S., Tobias, A. M., \& Walker, D. (2009a). Organizational and technological implications of cognitive machines: designing future information management systems. Hershey and $\mathrm{New}$ Y ork: Information Science R eference, IGI Global.

Nobre, F. S., Tobias, A. M., \& Walker, D. (2009c). The impact of cognitive machines in complex decisions and organizational change. J ournal of AI \& Society, 24(4), 365-381.

Nobre, F. S., Tobias, A. M., \& Walker, D. (2009b). The pursuit of cognition in manufacturing organizations. J ournal of M anufacturing Systems: Elsevier, 27(3), 145-157.

Nobre, F. S., Tobias, A. M ., \& Walker, D. (2010). New frontiers in industrial organizations: towards computational organizational management networks. Journal of Information Technology Research, 3(1), 43-54.

Oliveira, M. M., Jr. (1999). Core competenies and the knowledge of the firm. In A. Hitt, P. G. Clifford, R. D. Nixon, \& K. P. Coyne (Eds.), Dynamic strategic resources: development, diffusion and integration (pp. 17-42). New Y ork: Wiley.

Plutchik, R. (1982). A psychoevolutionary theory of emotions. Social Science Information, 21(4-5), 529-553.

Porac, J. F., \& Thomas, H. (2002). Managing cognition and strategy: issues, trends and future directions. In A. M. Pettigrew, H. Thomas, \& R. Whittington (Eds.), Handbook of strategy and management (pp. 165-181). London: Sage.

Ree, M. J., Carretta, T. R., \& Steindl, J. R. (2002). Cognitive ability. In D. S. Ones, N. A nderson, \& H. $K$. Sinangil (Eds.), Handbook of industrial, work and organizational psychology: personnel psychology (pp. 219-232). London: Sage.

Reed, S. K. (1988). Cognition: theory and applications (2nd ed.). Pacific Grove, CA: B rooks-Cole Publishing Company.

Schmidt, F. L., \& Hunter, J. E. (2000). Select intelligence. In E. A. Locke (Ed.), The blackwell handbook of principles of organizational behavior (pp. 3-14). Oxford, UK and Maiden MA: Blackwell Publishers.

Scott, W. R. (1998) Organizations: rational, natural, and open systems. N ew Jersey: Prentice Hall.

Simon, H. A. (1947). Administrative behavior: a study of decision-making processes in administrative organization. New Y ork, NY : M acmillan.

Simon, H. A. (1982a). Models of bounded rationality: economic analysis and public policy. Cambridge, M A : M IT Press. 
Simon, H. A. (1982b). Models of bounded rationality: behavioral economics and business organization (V ol. 2). Cambridge, M A : M IT Press.

Simon, H. A . (1983). Reason in human affairs. Stanford: Stanford University Press.

Simon, H. A . (1996). The sciences of the artificial (3rd ed.). Cambridge, M A : M IT Press.

Simon, H. A. (1997b). Administrative behavior: a study of decision-making processes in administrative organizations. New Y ork: The Free Press.

Simon, H. A. (1997a). Models of bounded rationality: empirically grounded economic reason (Vol. 3). Cambridge, M A : M IT Press.

Spender, J. C. (1996a). Making knowledge the basis of a dynamic theory of the firm. Strategic Management J ournal, 17(Special Issue), 45-62.

Spender, J. C. (1996b). Organizational knowledge, learning, and memory: three concepts in search of a theory. J ournal of Organizational Change Management, 9(1), 63-78.

Takeuchi, H., \& Nonaka, I. (2004). Hitotsubashi on Knowledge Management. Singapore: Wiley \& Sons.

Visser, M. (2007). Deutero-learning in organizations: a review and a reformulation. Academy of M anagement Review, 32(2), 659-667.

Walsh, J. P. (1995). M anagerial and organizational cognition: notes from a trip down memory lane. Organization Science, 6(3), 280-321.

Wiener, N. (1961). Cybernetics or control and communication in the animal and the machine (2nd ed.). Cambridge, M A : M IT Press.

Zadeh, L. A . (1965). Fuzzy sets. Information and Control, 8(3), 338-353.

Zadeh, L. A. (1973). Outline of a new approach to the analysis of complex systems and decision process. IEE E Transactions on Systems, M an, and Cybernetics, 3(1), 28-44. 